\title{
Construtos para modelagem de organizações fundamentadas na informação e no conhecimento no serviço público brasileiro
}

\author{
Ethel Airton Capuano \\ Doutorando em ciência da informação pela Universidade de Brasília \\ $(\mathrm{UnB})$; mestre em gestão do conhecimento e da tecnologia da \\ informação pela Universidade Católica de Brasília (UCB). \\ E-mail: eacapuano@terra.com.br
}

\begin{abstract}
Resumo
O artigo apresenta um estudo preliminar, com base na literatura e na experiência profissional dos autores, sobre as principais características da estrutura secular de organizações no setor público brasileiro, suas conexões epistemológicas com os conceitos de democracia e cidadania e uma proposta de modelo genérico de Organização Fundamentada na Informação e no Conhecimento (Ofic) para o provimento efetivo de serviços públicos no país. O conceito de Ofic deriva de construtos extraídos da ciência política, da administração pública, da gestão de tecnologia da informação e comunicação (TIC) e de abordagens pragmáticas de projetos de modernização dos serviços públicos para melhoria da qualidade e da eficiência no atendimento aos usuários. O modelo genérico de Ofic proposto busca uma síntese de teses burocráticas e gerencialistas para moldar um novo paradigma de gestão, baseado no uso intensivo da informação, no incentivo ao aprendizado e na gestão do capital intelectual nas organizações do setor público. Em termos estruturais, a metáfora do "lego" é utilizada para evidenciar os blocos de informações e as unidades de operações e decisões nos ambientes das organizações públicas, suas interfaces conversacionais internas e externas e sua dinâmica num contexto de transparência de gestão.
\end{abstract}

\section{Palavras-chave}

Modelo organizacional. Modelo informacional. Gestão da informação. Gestão do conhecimento. Gestão por processos. Gestão de serviços públicos. Tecnologia da informação e comunicação. Democracia.

Cidadania. Burocracia. Gerencialismo. Nova Gestão Pública.

Organização fundamentada na informação e no conhecimento.

\section{Constructs for modeling information and knowledge-based organizations (IKBO) in Brazilian civil service}

\begin{abstract}
This article shows a preliminary study, based on literature and professional experiences of the authors, about organizational models in the Brazilian public sector, its epistemological connections with the concepts of democracy and citizenship and a proposal for general model of Information and Knowledge-Based Organization (IKBO) to effectively provide public services in the country. IKBO concept comes from Political Science, Public Administration, Information and Communication Technology (ICT) Management and pragmatic approaches of public services for modernization projects to improve quality and efficiency in user attendance process. The general IKBO model proposed has the goal of a synthesis between bureaucratic and managerial theses to shape a new management paradigm based on intensive use of information and learning incentives, understanding that "knowledge management" is a meaningful concept only if based on information and intellectual capital management and other intangible organization assets.
\end{abstract}

\section{Keywords}

Organizational model. Informational model. Information management. Knowledge management. Process-based management. Public service administration. Civil Service. Information and communication technology. Democracy. Citizenship. Managerialism. New Public Management. Information and Knowledge-Based Organization.

\section{INTRODUÇÃO}

Desenvolve-se, neste artigo, (i) uma análise crítica do atual modelo de organização do serviço público brasileiro, predominantemente hierárquico-funcional e burocrático, (ii) dos construtos teóricos que têm sido utilizados, historicamente, pró e contra esse modelo, (iii) das tendências inerciais e (iv) uma abordagem pragmática proposta para um novo modelo de organização fundamentada na informação e no conhecimento (Ofic) para o setor público no país. Como o eixo estruturador das organizações do aparelho de Estado e dos principais serviços públicos brasileiros - educação, saúde, segurança e previdência social - encontra- se definido na Constituição Federal, tendo como espelhos as constituições estaduais e leis orgânicas municipais, podese pensar em um modelo básico comum de prestação de serviços públicos vigente em todos os entes federados e, por isso, pensar-se também em modelos de soluções genéricas para problemas sistêmicos, justificando-se a abordagem deste artigo. ${ }^{1}$

O encaixe do tema na ciência da informação se deve aos próprios fundamentos epistemológicos dessa área do conhecimento que se encontram, para alguns autores, na linha filosófica da fenomenologia (partindo de Platão e Aristóteles, passando por Kant, Husserl e Heidegger), na base de uma taxonomia original das coisas do mundo - o denominado Complexo M, integrado por matéria e energia, mais a informação como o princípio da organização das coisas, o elo entre matéria e energia (DE SIQUEIRA, 2008, p. 119). A informação nas organizações pode ser encarada como a cola conceitual que conecta as várias dimensões dessa complexidade, permitindo uma síntese das várias visões do conhecimento no tema, como a abordagem integradora de Choo (2003).

O tema é multidisciplinar, como a própria ciência da informação, e os construtos teóricos da análise buscam também nos conceitos de democracia e cidadania, ainda

${ }^{1} \mathrm{O}$ autor fundamenta esse axioma sistêmico também com observações empíricas de sua prática profissional de duas décadas na carreira de especialista em políticas públicas e gestão governamental (EPPGG) do Ministério do Planejamento, Orçamento e Gestão. 
que um tanto imprecisos sob certos aspectos, paradigmas para elaboração de modelos organizacionais baseados na informação adequados para enfrentamento dos desafios contemporâneos da administração pública. Outra abordagem adotada no modelo provém da linha fenomenológica da ciência da informação, com base no conceito de arquitetura da informação de Lima-Marques e Macedo (2006), explorando elementos ontológicos invariantes (onipresentes e genéricos) de sistemas de informação (SIs) nas organizações.

Os pontos de partida conceituais e históricos de administração pública no Brasil, que representam as outras dimensões complementares dessa multidisciplinaridade temática, encontram- se estruturados em várias obras sobre o tema, tais como as de Souza (1999), Santos (1997), Graham (1997), Carvalho (1996), Gomes, Dias e Motta (1994) e Teixeira e Totini (1991), que servem de base para reflexões profundas sobre os traços culturais e institucionais do Estado brasileiro, com suas virtudes e mazelas, e para insights acerca das necessidades de mudanças e caminhos possíveis.

Os elos entre a administração e a ciência da informação, no contexto das organizações, geralmente se encontram encapsulados em discussões sobre governo eletrônico (e-Gov), gestão da informação (GI), gestão do conhecimento (GC), gestão por processos, gestão do capital intelectual e aprendizado organizacional, abundando obras recentes, como as de Altman (2007), Ashraf, Ali e Ashraf (2005), Babilon (1998), Balanco e Leony (2007), Barbará (2006), Batista (2007), Campos (2007), CCMD (2007), Choo (2003), Choo (1991), Cong (2003), Davenport e Prusak (1998), Gore (1994), Hemsley e Vasconcelos (1997), Homburg (2004), Hood (1995), Hopkins (1982), Kent (2007), Kim e Lee (2006), Knight, Fernandes e Cunha (2007b), Lodi (1970), Magalhães, Matta, Guedes e Belens (2007), Mare (1998), Marini e Martins (2004), McInerney (2006a), Metastorm (2007), Nonaka e Takeuchi (1997), Palkovits e Wimmer (2007), Perrotti (2004), Pierozzi Jr., Miranda e Carvalho (2006), Ramanathan (2005), Ribeiro (2007), Riecken (2008), Ritto (2005), Salhofer e Ferbas (2006), Späth (2006), Sveiby (2001), Takahashi e Takahashi (2007), Tarapanoff (2006a), Tarapanoff (2006b), Traunmüller e Wimmer (2003), Usero e Orenes (2005), Valls (2004), Volberba (1998), Wilson (2002), Zell (1997) e outros.

Como motivação do artigo se encontra o enorme desafio, teórico e prático, de modernização do serviço público brasileiro em busca de sua legitimação perante a população, em um contexto democrático de cidadania.
O desafio consiste, do ponto de vista cognitivo, na elaboração de uma síntese conceitual entre o modelo burocrático e modelos mais gerencialistas que permita a modelagem das organizações do serviço público segundo as necessidades de seus usuários, tendo como condicionantes a evolução social e tecnológica em curso, e na sua exeqüibilidade prática sobre os substratos cultural-institucional, político, econômico e sociotécnico vigentes.

Considerando-se a complexidade natural do tema, entende-se que a superação dos problemas crônicos da administração pública no Brasil exigirá abordagens conceitualmente mais holísticas e pragmáticas, centradas na gestão da informação e do conhecimento (Gico) e nas tecnologias da informação e comunicação (TICs). O conceito de gestão do conhecimento adotado pelo autor, contudo, é um tanto cético, portanto wilsoniano (WILSON, 2002) e druckeriano (DRUCKER, 1994 e 1998), e mais centrado no conceito de gestão do capital intelectual e no uso intensivo de sistemas de informação (SI) baseados em computador como suporte a ambientes organizacionais de aprendizagem permanente e institucionalizada nos loci laborais. O tema Gico, portanto, integra no modelo proposto as dimensões pessoas e informação, enquanto TIC integra as dimensões processos e tecnologia na gestão corporativa.

A complexidade epistemológica inerente aos projetos de reforma do modelo de gestão no setor público no país se deve, em grande parte, às históricas contradições sociais e políticas do Estado brasileiro que moldaram suas atuais estruturas e instituições, evidenciadas, por exemplo, por Santos (1997), Graham (1997) e Carvalho (1996). O pensamento reformista, como se percebe dos trechos a seguir das obras de dois desses autores, é antigo e recorrente, porém pouco animador:

Como ponto central da reforma necessária, sobressai a institucionalização de um modelo de gestão democrática, retornando o caráter republicano do Estado (fim do caráter privado e patrimonial), redefinindo as relações entre público e privado com destaque para a abertura de espaços de controle da sociedade civil. Devem ser criados canais para a participação da sociedade na gestão pública viabilizando o controle social do Estado através da participação de usuários, funcionários e da cidadania em geral na gestão das políticas e serviços públicos, viabilizando a negociação transparente, pública, das prioridades e ações centrais de governo. [...] deve-se procurar extinguir a separação burocrática que existe entre Estado e sociedade [...]. (SANTOS, 1997, p. 278) 
[...] num dos melhores textos de sociologia politica produzidos durante o Império, Joaquim Nabuco desenvolve o argumento de que a escravidão, ao fechar alternativas econômicas para grande parte da população livre, fazia com que o funcionalismo público se tornasse a vocação de todos. Daí o número excessivo de funcionários que com seus magros vencimentos se tornavam os servos da gleba do governo, vivendo em terras do Estado, numa dependência que só aos mais fortes não quebrava o caráter. Escrevendo 85 anos mais tarde, Raymundo Faoro apresenta visão radicalmente distinta da burocracia imperial. Em sua ótica, tratavase de um grupo que se constituía em estamento e se tornaria árbitro da nação e das classes sociais, regulador da economia e proprietário da soberania nacional. A visão de Nabuco vincula-se à corrente que vê o Estado imperial submetido à propriedade da terra, representada pelos latifundiários em geral, pelas oligarquias regionais, ou pelos clãs locais. Com Faoro (ou este com eles) estão os que vêem no mesmo Estado um Leviatã presidindo aos destinos de uma sociedade inerte. A análise da burocracia, juntamente com a da elite, poderá permitir a superação do estilo dicotômico de análise mediante uma interpretação mais abrangente e mais dialética (CARVALHO, 1996, p. 129-130).

Outro aspecto característico das contradições históricas do modelo geral de organização burocrática do Estado brasileiro é o desalinhamento entre estruturas políticoadministrativas e projetos nacionais de longo prazo. E talvez a maior evidência disso seja a construção da capital Brasília, onde uma estrutura administrativa paralela às estruturas burocráticas tradicionais foi criada para execução do projeto (VASCONCELOS, 1989). Desde as primeiras reformas na década de 1930, com Getúlio Vargas no poder, tendo como exemplo a criação do Departamento Administrativo do Serviço Público (Dasp) (1938), passando pelo estatuto dos servidores públicos civis de 1952 (Lei no 1.711), a Comissão Amaral Peixoto de 1963, o Decreto-lei no 200 de 1967, a reforma da Nova República (1985-89), a reforma Collor (1990) e a reforma Bresser Pereira (1995-98), os reformistas têm concentrado esforços na solução (ou escamoteamento) de problemas da dimensão pessoas, com pouca ênfase nas dimensões processos e tecnologia, que constituem o tripé ontológico do pensamento organizacional desde os primórdios da administração como corpo de conhecimento das ciências sociais.

O texto que se apresenta altera essa prioridade, concentrando atenções nos modelos de organização e arquitetura da informação e de TIC, tendo como elemento integrador (ou cola) a informação, considerada insumo indispensável e, muitas vezes, o próprio produto na prestação de serviços públicos. O objetivo geral do modelo proposto continua sendo o mesmo colimado por outros pensadores reformistas do passado, ou seja, promover as "necessárias reformas administrativas indispensáveis para garantir a eficiência democrática” (GOMES; DIAS; MOTTA, 1994, p. 149). Contudo, uma questão inquietante motiva reflexões nessa área interdisciplinar: Que tipo de construto poderia estabelecer um fio lógico para uma análise estruturante e concisa do problema? Ou, em outras palavras: onde é que se encontra o ponto de partida para diagnósticos mais precisos e o esboço de soluções mais elaboradas, realistas e pragmáticas para o problema do modelo de gestão dos serviços públicos no Brasil?

\section{CONSTRUTOS TEÓRICOS}

\section{Ciência política}

O corpo de conhecimento da ciência política é promissor nesta temática, e Bobbio (1995), por exemplo, argumenta que o único modo de se entender democracia como contraposição a todas as formas de governo autocrático é considerando suas características intrínsecas: um conjunto de regras fundamentais que estabelece quem é autorizado a tomar as decisões coletivas e com quais procedimentos. Em geral, a literatura administrativa voltada para o setor público, concentrada neste segundo atributo taxonômico da democracia de Bobbio, envolve pensadores de várias disciplinas do conhecimento*.

Osborne e Gaebler (1995), entusiastas da renovação conceitual da administração no setor público com teses gerencialistas da corrente denominada Nova Gestão Pública (New Public Management - NPM), declaram que o pensador da administração que mais os influenciou foi Peter Drucker, que previu, em sua obra de 1968 A Era da Descontinuidade, a bancarrota do modelo burocrático de governo. Obras mais recentes, como as de Knight, Fernandes e Cunha (2007), Salhofer e Ferbas (2006), Homburg (2004), Marini e Martins (2004) e Santos (1997) constituem apenas uma amostra desse rico acervo.

O conceito de democracia direta, entretanto, vem acumulando interesse de partidos políticos de cultura

\footnotetext{
* Bobbio, argumentando sobre a promessa democrática não cumprida do governo dos técnicos, ressalta que tecnocracia e democracia são conceitos antitéticos, pois a democracia se rege pela hipótese que todos podem decidir sobre tudo (BOBBIO, 1995, p. 22-23).
} 
mais participativa no Brasil, coincidindo com a progressiva deterioração da imagem pública dos representantes eleitos. Com os resultados do plebiscito de 1993 (para adoção do sistema parlamentarista) e de 2006 (sobre o desarmamento da população) no Brasil, e do plebiscito na Venezuela em 2007 (sobre reeleições sem limites para presidente), também se apresentam evidências que desautorizam críticas simplistas sobre democracia direta, considerada populista, uma vez que em todas essas situações a decisão da maioria da população contrariou a vontade do governo e, em dois desses casos, a própria vontade do parlamento (plebiscito sobre o sistema de governo e referendo sobre o desarmamento, ambos no Brasil).

O modus operandi de um modelo democrático de organização governamental, para ser efetivo, deve ser reproduzido, conceitualmente, em todos os níveis administrativos do aparelho estatal, afirmação que parece tautológica, mas necessária para se compreender algumas tendências do pensamento temático na ciência política. Bobbio esclarece que não se pode mensurar o desenvolvimento da democracia apenas pelo número de pessoas que têm o direito de votar, mas pelo número de locais diversos na vida política do cotidiano nos quais se exercita o direito de voto. Ou, "para se julgar o estado de democratização de um determinado país, o critério não deve ser mais aquele de quem vota, mas aquele de onde se vota" (BOBBIO, 1995, p. 52). E nesse exato ponto reside o motivo pelo qual o modelo burocrático weberiano tem vínculos originais com a própria idéia de democracia, resistindo, conceitualmente, aos ataques dos pensadores gerencialistas da NPM - o Estado democrático, que contempla, inerentemente, demandas sociais difusas, é uma organização voltada para a prestação de serviços (BOBBIO, 1995).

O pensamento gerencialista, ao tentar livrar o exercício da gestão dos meios (recursos) do controle burocrático, concentrando-se na avaliação de resultados (ex-post), atinge em cheio algo que é caro ao ideário democrático - a participação do cidadão na vida da administração pública. O conceito de democracia envolve, vale ressaltar, tanto o controle dos meios como a avaliação dos resultados da gestão, o que equivale dizer que os processos decisórios são tão importantes para a democracia quanto as decisões em si e os resultados conseqüentes. Essa crítica de natureza política, que é extremamente contundente ao gerencialismo, argumenta que o modelo de políticas públicas da NPM é claramente desfavorável à participação do cidadão (ou cliente) na sua formulação, portanto socialmente excludente (BOX, 1998).
As críticas do pensamento burocrático não invalidam, no entanto, os méritos do pensamento gerencialista na administração pública, especialmente no que se refere a um ponto conceitual nevrálgico que compromete a credibilidade do modelo burocrático e, por conseqüência, a confiança nas estruturas e instituições do Estado democrático: a sua crônica incapacidade de produzir os resultados esperados pela sociedade usuária dos serviços públicos, especialmente aqueles estamentos sociais mais esclarecidos, no caso do Brasil geralmente representados, tipicamente, pelo contribuinte de classe média que arca com a maior parte da carga tributária sobre a renda das pessoas. Bobbio (1995) sintetiza esse estado natural de baixa efetividade no cumprimento de promessas da democracia argumentando que a democracia se caracteriza pela demanda fácil e resposta difícil, enquanto a autocracia, ao contrário, controla a demanda e tem maior facilidade para produzir resultados.

O livro de Bresser Pereira (1998), apesar de voltado para a divulgação do ideário gerencialista, é bastante didático, com conteúdos bem elaborados sobre o conceito de burocracia no serviço público e suas conexões com a organização do aparelho de Estado, servindo de referência recomendada para os iniciantes nesse debate contemporâneo.

\section{Administração pública}

Outro ponto de reflexão é que esse Estado de prestação de serviços de Bobbio (1995) se parece com uma organização baseada na informação (OFI) de Drucker (1994), ou seja, uma grande e complexa organização cujo principal insumo e produto é predominantemente informação. Considerado o maior pensador da administração no século XX, Drucker (1994) rememora, a propósito, um modelo histórico de organização fundamentada na informação $(\mathrm{OFI})$ da época vitoriana bastante didático e paradigmático pela sua simplicidade, efetividade, eficácia e eficiência: a inteligente organização do serviço civil britânico na Índia colonial, onde, com um contingente relativamente reduzido de funcionários públicos distribuídos num vasto território, o império britânico administrou por mais de dois séculos um vasto e complexo país como a Índia.

Choo (1991) apresenta uma revisão de literatura bastante exaustiva para compreensão dos fundamentos científicos da racionalidade de diversos modelos de organizações tradicionais, inclusive do modelo hierárquico-burocrático, esboçando, ainda que timidamente, um modelo informacional de organização estático. Em sua obra mais recente, contudo, esse autor apresenta talvez a síntese 
cognitiva mais consistente produzida sobre o problema das organizações complexas em face dos fenômenos de processamento e interpretação de informações, aprendizado e tomada de decisões em ambientes de incerteza (CHOO, 2003).

O diagnóstico atual mais comum sobre a burocracia é que o modelo não contribui mais para uma esperada evolução no serviço público cujo objetivo é torná-lo não apenas mais includente no sentido social, mas eficaz e eficiente e, com isso, satisfazer às necessidades crescentes e cada vez mais plurais de uma sociedade complexa e ansiosa por mais cidadania.

O texto de Marini e Martins (2004), por exemplo, é bastante denso e conceitualmente ilustrativo do caso brasileiro, contextualizando os problemas do modelo burocrático na execução do Plano Plurianual (PPA) federal de investimentos do período 1999-2001. O espírito reformador desses autores é inspirado nas obras pioneiras de autores gerencialistas, tais como Osborne e Gaebler (1995), os reformadores ingleses e Bresser Pereira (1998) no Brasil. Esses autores apresentam críticas bem elaboradas ao modelo hierárquicoburocrático em seu contexto brasileiro, mas evitam a análise histórica e cultural da dinâmica do serviço público. $\mathrm{O}$ aspecto mais interessante de sua obra mais recente é a proposição de um modelo matricial de estruturas para os órgãos públicos para interações laterais, ou transversais, algo necessário na execução de projetos multidisciplinares de políticas públicas, um ponto de partida conceitual bastante promissor para pesquisas ulteriores no tema (MARINI; MARTINS, 2004).

Homburg (2004) conceitua a Nova Gestão Pública (NPM), de modo simplista (como o próprio autor admite), como um conjunto de estratégias e táticas que procuram melhorar a capacidade dos órgãos de governo e suas entidades colaboradoras privadas e do terceiro setor para produzir resultados mediante a reinvenção do governo. O autor observa que o paradigma tradicional (weberiano) de administração pública tem sido criticado desde os anos 1970 pelo seu desempenho insatisfatório, na prática, e que a intensificação do ressentimento dos cidadãos com o serviço público coincidiu com o desenvolvimento acadêmico de teorias econômicas, como o neoinstitucionalismo, e teorias administrativas ancoradas na ciência política, como a da escolha pública, resgatando a contratualização mercantil como modelo de transação na estrutura de governança do setor público.

Com a NPM, emergiu uma nova retórica de livre escolha do cidadão (ou cliente) quanto às entidades provedoras de serviços públicos, o que implicaria certa concorrência entre mais de uma entidade na prestação dos serviços, que seriam cobradas pelos resultados, e não pelos meios empregados para tanto. Osborne e Gaebler (1995) argumentam que se o objetivo é uma gestão melhor devese libertar as mãos dos gerentes e deixá-los gerenciar, responsabilizando-os pelos resultados e não pelo cumprimento de regras burocráticas. Em suma, as características conceituais da NPM são (HOMBURG, 2004, p. 549):

- orientação ao usuário dos serviços públicos mais como 'clientes' do que como 'cidadãos';

- orientação das organizações públicas ao desempenho;

- orientação à melhoria contínua da qualidade;

- estruturas enxutas e descentralizadas, com empoderamento dos servidores públicos que operam os serviços (servidores do 'chão-de-fábrica'*);

- rigorosos mecanismos de controle de custos;

- ênfase na responsabilização dos escalões superiores pelo desempenho em unidades descentralizadas ou mesmo privatizadas;

- flexibilidade no recrutamento, seleção e dispensa de pessoal, com orientação ao desempenho;

- uso de estruturas divisionais para quebrar unidades burocráticas tradicionais;

- gestão mais ativa e emancipação das habilidades de gestão operacionais.

Outro aspecto importante para a análise crítica da NPM é a contratualização dos níveis de desempenho e consumo de recursos das organizações públicas. $\mathrm{O}$ instrumento proposto pelos reformadores é o contrato de gestão, no qual organização prestadora de determinados serviços públicos assume com os órgãos contratantes no núcleo duro do governo compromissos de entregas de determinados serviços de sua competência à clientela na população, com certos níveis de qualidade e preços (orçamento) predefinidos. As críticas à NPM são várias e contundentes, tais como o isolamento de uma organização assim contratualizada em relação às demais organizações do serviço público, perdendo-se com isso a noção de conjunto e oportunidades de ações e projetos sinérgicos ou complementares envolvendo várias organizações simultaneamente em torno de objetivos e metas comuns.

\footnotetext{
* Interpretação contextual do termo, em inglês, street workers.
} 


\section{Tecnologia da Informação e Comunicação}

O cenário mundial das organizações públicas em relação ao uso de TIC evidencia crises e desafios formidáveis para os próximos anos. Pawlowski, Datta e Houston (2005), por exemplo, relatam uma série de problemas enfrentados atualmente pelos estados norte-americanos na competição por profissionais talentosos no mercado:

I. demanda crescente de mão-de-obra qualificada para seus departamentos técnicos em razão do aumento da confiança dos governos na TIC para a operação de seus programas e provimento de serviços aos cidadãos;

II. Dificuldade de competição com empresas do mercado no recrutamento de talentos em razão do desnível salarial geral (menos atrativos no serviço público);

III. envelhecimento de sua força de trabalho (os autores mencionam relatórios do Council of State Governments dos EUA estimando uma redução natural de 30\% de pessoal em 2006 em razão de aposentações);

IV. mesmo durante os períodos de retração da atividade econômica e da conseqüente redução da arrecadação de impostos, a demanda por alguns serviços públicos baseados em TIC tem aumentado continuamente (processamento de benefícios do seguro-desemprego, por exemplo).

O caso do mercado de trabalho de profissionais de TIC nos EUA sugere ser ainda mais dramático, pelas previsões oficiais, em razão do declínio do interesse dos mais jovens nesse tipo de carreira (PAWLOWSKI; DATTA; HOUSTON, 2005). Entretanto, esses dados sobre demandas crescentes de profissionais de TIC para as organizações constituem apenas uma visão acima da linha d'água do fenômeno informacional (BATES, 2007), suscitando-se questões como: Quais são os vetores sociotécnicos de crescimento dessa demanda? E como resolver o problema?

O caso das organizações públicas brasileiras não é diferente, na essência, em nenhum dos problemas apresentados nos estados norte-americanos, pois, apesar das demandas crescentes de serviços de TIC para suportar a modernização tecnológica dos serviços públicos, as empresas estatais de TIC enfrentam dificuldades na retenção de talentos. E, para piorar o cenário, a força de trabalho nos quadros governamentais está envelhecendo, com média etária de 46 anos nos órgãos da União, conforme dados da Secretaria de
Recursos Humanos do Ministério do Planejamento, Orçamento e Gestão (SRH/MP, 2007). Em contrapartida, o oposto ocorre do lado da demanda por aquilo que Knight, Fernandes e Cunha (2007) denominam e-democracia, com pressões populares exigindo sempre melhores serviços baseados em informação processada nos sistemas computacionais governamentais.

Bobbio (1995) afirma que todo Estado muito democrático é, ao mesmo tempo, muito burocrático, porque o processo de burocratização tem sido, em grande parte, uma conseqüência do processo de democratização. Essa observação, ainda que óbvia, merece atenção porque burocracia implica controles dos agentes públicos, e controles dos meios, em processos burocráticos, encontra apoio tecnológico natural nos sistemas de informação (SIs) baseados nas TICs, pelo seu mecanicismo lógico. Os exemplos, no serviço público brasileiro, são vários e não há como negar suas contribuições ao processo de democratização do país, sendo os mais notáveis casos de sucesso, no governo federal, os sistemas de contabilidade e orçamento públicos (Siafi e Sidor, implantados no período 1985-89), de folha de pagamento (Siape, no período 1990-95), de eleições eletrônicas (urna eletrônica, em 1998), de declaração de imposto de renda de pessoa física pela Internet (em 1998), de compras governamentais (Comprasnet, em 2002) e de integração de transações interbancárias (SPB, em 2002).

Outros exemplos de aplicação de TIC para ampliação do acesso aos direitos dos cidadãos e controle dos agentes públicos, a partir do acesso à informação governamental, podem ser analisados e importantes lições extraídas, por exemplo, dos vários casos relatados por Bhatnagar (2003) em países do grupo Brica (Brasil, Rússia, Índia, China e África do Sul). O crescimento do uso de sistemas de informação (SIs) baseados em redes de computadores pelos governos no Brasil tem sido tão intenso, com despesas relativamente tão expressivas, que o Tribunal de Contas da União (TCU) criou, em 2006, uma secretaria especial com auditores especializados em questões envolvendo TIC na administração pública federal.

Outro fenômeno social vem ocorrendo silenciosamente, no mundo todo, com impactos profundos sobre a democracia, as organizações do serviço público, a ciência da informação e a computação eletrônica: o avanço da denominada sociedade da informação e do conhecimento de Masuda (1981) e outros profetas sociotécnicos. Como prova da realização dessa previsão, 
Wolff (2005) descobriu que os profissionais da informação nos EUA ampliaram sua participação no mercado de $42 \%$ da força de trabalho em 1960 para 53\% em 1980, e de 37\% em 1950 para 59\% em 2000. E observou, com análises estatísticas de dados dos censos nos EUA, que o agrupamento denominado trabalhadores do conhecimento cresceu, de 1950 a 2000, a uma taxa anual de $3,1 \%$ relativo ao total da força de trabalho naquele país, constituindo o agrupamento com crescimento mais intenso no período. Em conjunto, Wolff (2005) revela que os profissionais da informação ampliaram sua participação no mercado de trabalho à taxa de 2,6\% ao ano nesse mesmo período, contrastando bastante com a taxa de crescimento da participação dos demais agrupamentos profissionais, que foi de apenas $0,8 \%$ ao ano.

A pesquisa de Wolff (2005) mostra também um resultado curioso nos EUA: o crescimento em ritmo menor e até um declínio em 2000 da participação dos profissionais de serviços, o que sugere certa superposição de categorias com funções um tanto comuns, como profissionais do conhecimento, profissionais de dados e profissionais de serviços. O trabalho desse pesquisador confirma a estreita conexão entre evolução da TIC e da participação do profissional da informação no mercado observando-se o crescimento mais acelerado do agrupamento profissional do conhecimento após o boom dos computadores eletrônicos no mercado nos anos 1980 (ou o novo paradigma tecnoeconômico de Machlup).

Os vetores de crescimento da demanda por talentos nas funções públicas correlatas à gestão da informação e de TIC, portanto, são evidentes, podendo ser sintetizados em:

a) transformação sociotécnica acelerada das economias capitalistas e pseudocapitalistas (WOLFF, 2005);*

b) pressões sociais pela ampliação continuada da cobertura dos serviços públicos prestados pelos Estados democráticos de direito (BOBBIO, 1995);

c) anseios sociais pelo exercício da cidadania por meio, inclusive, do acesso às informações governamentais pela Internet e World Wide Web, sintetizados nas propostas de governo eletrônico (ou e-Gov) (KNIGHT; FERNANDES; CUNHA, 2007b);

\footnotetext{
* Como economias pseucapitalistas são consideradas, no contexto, as economias capitalistas com acentuada intervenção do Estado na atividade econômica, como os Tigres Asiáticos dos anos 1980 e os países em desenvolvimento do grupo BRICA (Brasil, Rússia, Índia, China, África do Sul).
}

d) aumento da complexidade dos SIs governamentais e das TICs de suporte;

e) falência conceitual e obsolescência tecnológica dos grandes SIs estruturantes legados das organizações públicas (HOSKINS; DOBERNACK; KUPTSCH, 2001; CAPUANO, 2006).

Como resolver esses problemas talvez seja um desafio a ser encarado pelas sociedades e seus governos nas próximas décadas. Entretanto, alguns caminhos possíveis no sentido de viabilidade podem ser discutidos no momento atual e iniciada sua implementação, assumindose certas premissas realistas sobre a cultura, o arcabouço institucional (em parte jurídico-normativo, em parte político), os modelos organizacionais e o contexto do serviço público no Brasil.

\section{PREMISSAS E MODELOS DERIVADOS DE Ofic}

\section{Premissas de Conjuntura}

O setor público no Brasil de hoje se insere em um contexto positivo do ponto de vista econômico, com estabilidade da moeda, crescimento continuado e certo controle das despesas públicas e, do ponto de vista social, com políticas de assistência social compensatórias de relativo êxito como colchão de alívio contra a miséria absoluta, além da universalização crescente dos serviços públicos de saúde. Em termos políticos, também se observam avanços, ainda que claudicantes, na democracia e na cidadania.

Como pontos negativos, são comuns as críticas populares à segurança pública, à educação pública (de baixa qualidade), à (pesada) carga tributária, aos juros (altos, estratosféricos em relação ao resto do mundo), ao (pouco) dinamismo econômico, à (baixa) qualidade dos serviços públicos em geral, ao clientelismo político e à acentuada percepção de corrupção. $\mathrm{O}$ traço histórico indelével do clientelismo e de práticas não republicanas na política brasileira pode ser estudado, por exemplo, na monumental obra de Graham (1997).

Os desafios econômicos e sociais que então se apresentam aos governos em geral, no Brasil, são vários, sendo os principais apresentados no seguinte decálogo: (i) manter a estabilidade macroeconômica, (ii) tornar o Estado uma eficaz e eficiente alavanca do desenvolvimento econômico, (iii) manter e ampliar (se possível) o alcance social das políticas assistencialistas compensatórias de combate à miséria, (iv) manter, ampliar a cobertura e melhorar a qualidade dos serviços 
de saúde pública, (v) melhorar a qualidade do ensino público, (vi) investir, em parceria com a iniciativa privada, em infra-estrutura, (vii) não aumentar a carga tributária, (viii) reduzir os juros básicos da economia, (ix) melhorar, dramaticamente, a segurança pública, $(\mathrm{x})$ desenvolver a democracia e a cidadania.

E, do ponto de vista administrativo, acumulam-se problemas de gestão, como carência de quadros qualificados em tecnologias em geral, sistema de mérito implantado apenas parcialmente, grade remuneratória e de aposentadorias e pensões caótica, modelo de carreiras errático, processos de trabalho obsoletos e com altos custos de transação (modelados para o padrão Gutenberg*) e a quase onipresente corrupção. A proliferação excessiva de ministérios pelo critério político e as resistências a mudanças advindas de históricos nichos de poder político com características patrimonialistas, clientelistas, fisiologistas, corporativistas e nepotistas também contribuem para essa situação adversa.

Os desafios, entretanto, são inafastáveis, com pressões populares crescentes no sentido de melhorar o desempenho da segurança, educação e serviços públicos em geral, aumentar os mecanismos de transparência das atividades dos governos e melhorar a qualidade dos gastos públicos (ou fazer a coisa certa com mais eficiência). Como problemas mais visíveis (acima da linha d'água) aos usuários dos serviços públicos, que interessam na análise informacional e tecnológica das organizações públicas neste artigo, alguns são conhecidos e comentados por autores como Marini e Martins (2004), Knight, Fernandes e Cunha (2007a), Hoskins, Dobbernack e Kuptsch (2001) e outros: desempenho insatisfatório de projetos transversais envolvendo vários órgãos, qualidade dos dados dos SIs governamentais geralmente insatisfatória, SIs pouco integrados (ilhas de dados), arquiteturas de informação e de TICs caóticas.

\section{Premissas institucionais}

As premissas institucionais de modelagem mais estáveis no cenário da típica organização pública brasileira são:

- modelo secular hierárquico-burocrático de administração;

- quadros de pessoal estáveis na base e rotativos no topo da pirâmide hierárquica;

\footnotetext{
" Intensivo no uso do papel como suporte aos fluxos e armazenamento de informação.
}

- quadros da base com estabilidade constitucional no emprego;

- quadros da base um pouco envelhecidos e de qualificação variável;

- concentração de quadros, na base, voltados para atividades burocráticas.

Os modelos possíveis de organização para o setor público no Brasil, discutidos mais adiante, são baseados nessas premissas.

\section{Modelagem e ciência}

O esboço de modelos de organizações fundamentadas na informação e no conhecimento (Ofics) com um apelo mais pragmático, sem atacar o modelo hierárquicoburocrático em sua essência, parece uma tendência e uma via de desenvolvimento de pesquisas no tema, principalmente porque, mesmo no caso de uma guinada mais radical em direção ao gerencialismo, seria exigida uma fase de transição com a inevitável convivência, talvez por décadas, de ambos modelos. A literatura mostra que o foco de interesse do pensamento reformista dos entusiastas do governo eletrônico (e-Gov) não se detém em discussões filosóficas sobre a burocracia, concentrando-se, antes, na busca de soluções práticas que contribuam para a superação dos crônicos 'gargalos' de desempenho do modelo hierárquico-burocrático com reengenharia de processos e uso mais intensivo de TIC.

Os conceitos de e-administração, e-serviços e e-democracia de Barbosa, Faria e Pinto (2007), por exemplo, depositam no uso estratégico de TIC o êxito de um novo modelo de gestão pública, mas não se detêm no detalhamento desse novo modelo. Esses autores encaram a NPM como um conceito genérico de reformas gerenciais no serviço público, argumentando que, embora a idéia de e-governo seja freqüentemente associada ao uso de TIC para a entrega de serviços, os conceitos subjacentes incluem melhoria nos processos, aumento da eficiência, melhor governança, elaboração e monitoramento de políticas públicas.

É pensada, na proposta de modelo, uma analogia com o modelo de derivação da matemática, com base no conceito de função derivada, um tipo de função que é a base do cálculo diferencial e permite que o analista, conhecendo o valor relativo da primeira derivada de uma função (que é um modelo matemático) em um ponto de interesse, possa prever a evolução, ou extrapolação lógica, dessa função-modelo em relação a determinada variável do modelo (o tempo, por exemplo). A derivada 
primeira de uma função no plano (bidimensional) também tem um significado geométrico-analítico, mostrando a inclinação da reta que tangencia a superfície da função-modelo no ponto analisado, o que mostra se a função tende a ter os valores das variáveis independentes (de saída do modelo) crescentes, estáveis (iguais a zero) ou decrescentes em função da variável dependente. Em termos práticos, a analogia do modelo proposto de Ofic com a função derivada serve para mostrar a importância de se ter um ponto de apoio lógico em um modelo funcional em ciências sociais, para se conhecerem prováveis evoluções desse modelo original (no caso, o modelo hierárquico-burocrático).

Michaud (2006b) argumenta que um modelo sobre algum fenômeno encerra conhecimento sobre esse fenômeno, sendo considerada a modelagem, portanto, um método científico. Kneller (1980) comenta sobre a polivalência do termo modelo, na ciência, observando que existem modelos com funções representacionais, teóricas e imaginárias. A modelagem é uma atividade comum dos profissionais da ciência da computação nas fases iniciais de projetos de SIs, embora essa atividade, na metodologia de desenvolvimento de sistemas de informação orientada a objetos (OO), também possa ser considerada área de competência dos cientistas da informação, com forte apelo cognitivo para questões ontológicas de arquitetura da informação (AI)* , comunicação da informação e gestão da informação e do conhecimento. Silva (2004), por exemplo, mostra como um framework** metodológico de aquisição de conhecimento pode contribuir para a própria melhoria do desempenho dos processos de desenvolvimento de SIs computacionais.

\section{MODELO VIÁVEL DE Ofic}

\section{Variáveis}

Com o balanço geral das percepções dos autores referenciados neste artigo, pode ser elaborada uma matriz SWOT genérica das organizações públicas no Brasil, elicitando-se, resumidamente, as variáveis relativas a seus pontos fortes (Strength), pontos fracos (Weakness), oportunidades (Opportunities) e ameaças (Threats) do ambiente externo. $\mathrm{O}$ ambiente externo, no caso, pode

\footnotetext{
* O conceito de Arquitetura da Informação adotado neste artigo, baseado em Lima-Marques e Macedo (2006), refere-se mais a uma abordagem de raciocínio fenomenológico sobre os ambientes informacionais do que artefatos de representação da informação.

** Entendido como um modelo genérico de solução de problemas de um determinado domínio.
}

ser considerado como composto do resto das organizações do país e sua população, além de organizações e países estrangeiros. O objetivo do método analítico SWOT é definir estratégias para manter e ampliar os pontos fortes da organização e reduzir os riscos decorrentes dos pontos fracos aproveitando-se as oportunidades e reduzindo-se as ameaças. As vantagens do método são simplicidade, baixo custo relativo de aplicação, flexibilidade, capacidade de integração da informação e estímulo à colaboração de todas as áreas da organização para sua consecução.

Os pontos fortes correspondem aos recursos considerados importantes da organização que podem ser combinados para o alcance de objetivos e metas; os pontos fracos correspondem aos pontos vulneráveis que limitam ou reduzem sua capacidade de progresso; as oportunidades são forças ambientais que não estão sob a governabilidade da organização, mas que podem favorecê-la em sua posição estratégica, desde que conhecidas e aproveitadas adequadamente; ameaças são forças ambientais que não estão sob a governabilidade da organização e que criam obstáculos ao seu êxito, mas que podem ser evitadas se conhecidas a tempo e tomadas as medidas adequadas.

As conclusões deduzidas da literatura, do arcabouço institucional e da realidade observável no dia-a-dia da administração pública federal no Brasil, assumidas como axiomas neste estudo em função das quais podem ser elicitadas as variáveis para composição da matriz SWOT, são resumidas a seguir:

I. o nível político-estratégico das organizações públicas em geral não serve de ponto de apoio para reformas de longo prazo devido ao seu alto turn over;

II. os quadros da base da pirâmide têm estabilidade no emprego;

III. os quadros da base da pirâmide e da média gerência têm conhecimento e longa experiência de execução dos processos de trabalho;

IV. os quadros de média gerência e da base da pirâmide apreciam projetos de modernização dos serviços com uso intensivo de TIC, podendo-se constituir pontos de apoio para projetos de longo curso;

V. com média etária dos quadros em torno de 46 anos, inclusive em funções operacionais, previsão de aposentadoria em massa nos próximos 10-15 anos e dificuldade de renovação dos quadros em funções 
operacionais pela concorrência em desvantagem com o mercado, há expectativa de redução progressiva dos quadros mais experientes no nível operacional das organizações públicas nos próximos anos;

VI. a tendência de dispersão da força de trabalho em um número excessivo de órgãos criados com critérios apenas políticos não permitirá a concentração de expertise e de processos de trabalho compartilhados para otimização e aumento da eficiência do conjunto de órgãos sequer em um nível de governo;

VII. existe uma carência de sínteses epistemológicas em relação a modelos desejáveis e viáveis de organização dos serviços públicos, pois os modelos teóricos em debate para reforma do serviço público, representados predominantemente por idéias da NPM e e-Gov, com ressalvas do modelo hierárquico-burocrático em relação aos controles a priori, são conceitualmente conflitantes e precisam de abordagens sintéticas, com pontos de convergência que possam reduzir resistências para sua implantação;

VIII. os governos em geral, no Brasil, apresentam modelos de gestão fragmentados (MARTINS, 2004), desintegrados, nos quais as secretarias de gestão, em vez de representarem um locus abrangente de discussão de modelos de gestão multidisciplinares, concentram-se geralmente em questões de gestão de pessoal; os próprios modelos de e-Gov dos governos estaduais e municipais no país, conforme se pode observar nos resultados das pesquisas de Riecken (2008), não apresentam resultados promissores, estagnando no $1^{\circ}$ e $2^{\circ}$ estágios de utilização, principalmente devido ao desalinhamento estratégico em relação aos processos de trabalho das organizações;

IX. como se pode observar dos projetos de modernização em curso nos órgãos públicos em geral, existe ênfase em investimentos em TIC, e não em informação e conhecimento;

X. os modelos de processos redesenhados não são implementados em conseqüência de resistências políticas e corporativas, pois implicam alterações na estrutura de poder na organização;

XI. o estilo de governança na gestão de dados, informação, conhecimento e TIC é predominantemente feudal, no qual cada departamento busca maximizar os benefícios apenas para sua área de interesse, sem preocupação com as necessidades de compartilhamento de conteúdos e oportunidades de esforços e resultados sinérgicos compartilhados com o resto da organização (WEILL; ROSS, 2004);

XII. em geral, a arquitetura de informação das organizações governamentais é caótica;

XIII. as políticas de capacitação de pessoal não têm sido, em geral, priorizadas pelos governos, revelando-se periféricas e inefetivas;

XIV. existem ilhas de excelência no serviço público e funcionários dispersos nas organizações públicas com alta qualificação técnica e de gestão que podem ser úteis na formulação de projetos de modernização dos serviços públicos;

XV. existe pressão da população pela modernização dos processos de prestação de serviços públicos de modo a torná-los mais confortáveis e eficientes;

XVI. observa-se queda acentuada nos preços de microcomputadores e popularização do mercado de serviços de telecomunicações e acesso à Internet no nível individual, contribuindo para a aceleração da inclusão digital das classes sociais de menor renda;

XVII. em geral, o contribuinte concorda com a manutenção da carga tributária elevada, desde que o retorno social se concretize, efetivamente, com uma melhoria dramática da qualidade dos serviços públicos em geral, especialmente nas áreas de educação, saúde, segurança e transportes públicos;

XVIII. existe uma tendência em que organizações do terceiro setor podem vir a assumir, em determinadas circunstâncias políticas, jurídicas e sociotécnicas, funções antes exercidas por organizações do serviço público, em conseqüência da incapacidade de as organizações públicas gerarem resultados satisfatórios;

quadro 1, a seguir, mostra sinteticamente, em uma matriz SWOT, essas opiniões e percepções (enumeradas em algarismos romanos) condensadas da revisão de literatura e de observações empíricas, permitindo classificar-se, como diagnóstico do setor público no Brasil, pontos fortes e fracos e oportunidades e ameaças para o futuro. 
Matriz SWOT Genérica das Organizações Públicas no Brasil

\begin{tabular}{|l|c|c|}
\hline \multirow{2}{*}{ Ambiente Externo } & \multicolumn{2}{|c|}{ Recursos Competitivos } \\
\cline { 2 - 3 } & Pontos Fortes & Pontos Fracos \\
\hline Oportunidades: XV, XVI, XVII & III, IV, XIV & I, II, V, VI, VIII, IX, X, \\
\cline { 1 - 1 } Ameaças: VII, XVIII & & XI, XII, XIII \\
\hline
\end{tabular}

Classificadas genericamente dessa forma, as variáveis consideradas como pontos fortes que podem ser úteis na exploração de oportunidades são de natureza eminentemente sociotécnica, relativas ao capital intelectual das organizações do serviço público. Os pontos fortes que podem contribuir para o enfrentamento de ameaças, como, por exemplo, propostas de privatização (pelo menos operacional) dos serviços públicos, são de natureza econômica e social, e os usuários pressionam pela melhoria da qualidade e estão dispostos a pagar por essa qualidade e o mercado oferece condições econômicas que viabilizam a execução de projetos com uso intensivo de TIC (pontos fortes em sinergia com oportunidades combatendo ameaças).

É fácil observar, também, que as variáveis relativas aos pontos fracos se devem às históricas contradições do arcabouço institucional*, resultado dos modelos de representação política, do modelo administrativo vigente e das lacunas epistemológicas no tema. Em relação à rotatividade no topo da pirâmide organizacional, parece que a acefalia intermitente é um traço marcante da administração pública no Brasil, e nada se poderá fazer até que reformas políticas bastante profundas e impactantes se tornem realidade.

Quanto à estabilidade no emprego, ela é considerada como ponto fraco porque constitui um fator de acomodação e conformismo natural dos servidores públicos em relação ao status quo, tornando-os algo "mitridizados** em relação às críticas que pairam sobre suas organizações, muitas vezes testemunhas silentes e impotentes de situações adversas para os usuários dos serviços públicos (ALMEIDA, 2007).

Entretanto, a estabilidade no emprego, a exemplo do modelo sociotécnico da indústria japonesa (NONAKA; TAKEUCHI, 1997), contribui para um acúmulo

* Conforme Abrúcio (2008), essas condições mostram um Brasil novo, com instituições democráticas modernas, em constante luta contra um Brasil arcaico e decadente que teima em permanecer na cena política.

** Com alusão ao comportamento do rei grego Mítrides (Mithridates $\mathrm{VI})$, que tomava pequenas doses de veneno como vacina contra doses maiores previstas em futuros atentados de envenenadores a soldo de seus inimigos e, assim, tornava-se insensivel aos seus efeitos. histórico de capital intelectual, que é o alicerce real de projetos de gestão do conhecimento tácito (gestão do capital intelectual) nas organizações do serviço público.

O problema das perdas de pessoal experiente na gestão de processos nos próximos anos será um fator de crise mundial nas organizações não somente públicas, mas também em entidades privadas, e a solução do problema ainda requer o desenvolvimento de estratégias mais elaboradas, devendo-se, por uma questão de pragmatismo imediato, tratá-lo como uma condição de contorno apenas. Os problemas relativos à expertise e estilos de governança são objetos de interesse neste artigo e endereçados, ainda que superficialmente, no modelo geral de organização baseado na informação e no conhecimento (Ofic) proposto a seguir.

Com o modelo Ofic pretende-se uma solução para a redução dos efeitos das fraquezas das organizações públicas no longo prazo, encapsulando informações essenciais derivadas do conhecimento tácito de servidores públicos experientes em códigos de software para automação de processos. O efeito esperado dessa manobra é a capacidade de operação de modo mais automático possível, com transparência, eficácia e eficiência, mas com um número de servidores públicos experientes menor que o atual.

\section{Modelo Geral}

Os modelos gerais de organizações baseadas em informação e conhecimento (Ofics) para provimento de serviços públicos propostos neste artigo deverão atender aos seguintes requisitos, que podem ser considerados diretrizes gerais:

a) necessidade de reengenharia e automação acelerada de processos de trabalho com uso intensivo de TIC, com base na socialização e explicitação do conhecimento (NONAKA; TAKEUCHI, 1997)*, em razão da eminência

\footnotetext{
* Os grandes bancos de dados estruturadores da ação governamental ainda se restringem, em geral, à arrecadação de impostos e contabilidade pública, apoiando a ação fiscal dos governos, mas não suportam a automação dos fluxos de trabalho e do trânsito de documentos eletrônicos nos processos burocráticos das organizações do setor público.
} 
de aposentadoria em massa dos servidores públicos mais experientes previstas para a próxima década;

b) necessidade de conquistar o pessoal da base para garantir apoio vigoroso e continuado em projetos reestruturantes de longo prazo com uso de TIC;

c) concentração dos quadros em atividades mais ricas em conhecimento e menos operacionais (análise e avaliação, em vez da operação, de processos), em razão da previsível redução natural e gradativa de quadros operacionais;

d) necessidade de enriquecimento das atribuições e definição de competência essenciais para atuação, no nível operacional, no conceito de equipe (team) ad hoc, com missão específica e, muitas vezes, de curta duração;

e) necessidade de se preverem interfaces de uma organização para troca de dados e informações com as demais e, eventualmente, a constituição de organizações virtuais baseadas na informação e no conhecimento (Ofics) a partir de subdivisões virtuais de organizações preexistentes;

f) necessidade de se preverem ontologias interoperáveis elaboradas para composição de repositórios integrados de conteúdos informacionais de governo;

g) necessidade de apresentar resultados periodicamente para manter o patrocínio institucional aos projetos.

O esquema pictórico de representação de blocos ontológicos de construção de estruturas, processos e SIs de suporte tecnológico da figura 1 mostra como seria o modelo de Ofic proposto, onde as extensões das superfícies de contato entre os blocos indicam as interfaces conversacionais predominantes no modelo. Ou seja, essas interfaces mostram os pontos de interação entre grupos de atores nas organizações e os acessos necessários aos respectivos SIs* de suporte às suas atividades.

Como exemplos: (i) o Conselho de Cidadãos precisa acompanhar, em alto nível, os direcionamentos políticos dos órgãos públicos a partir dos contatos com os

\footnotetext{
* CRM: Gerenciamento do Relacionamento com a Clientela (Custom Relationship Management); DW: Armazém de Dados (Data Warehouse); ECM: Gerenciamento de Conteúdos Corporativos (Enterprise Content Management); ERP: Planejamento de Recursos Corporativos (Enterprise Resource Planning); GAI: Gestão de Ativos Intangiveis; GCI: Gestão do Capital Intelectual; OLTP: Processamento de Transações em Linha (On-line Transaction Processing); SCM: Gerenciamento da Cadeia de Suprimentos (Supply Chain Management); WP: Ponto Único de Acesso aos Sistemas de Informações da Organização na World Wide Web (Web Portal).
}

dirigentes e gerentes em todos os níveis, inclusive nos níveis operacionais de atendimento ao público e gestão de processos, pois os conselheiros deverão auscultar os usuários dos serviços e apresentar suas reivindicações de melhorias aos dirigentes da organização; (ii) o grupo de Direção Política precisa estar em contato permanente com o grupo de Gestão Interna, para acompanhamento das operações de suporte aos processos de negócio, mas também de olho nas informações produzidas pela Controladoria (os indicadores de produtividade e qualidade, por exemplo, ou mesmo desvios de comportamento como erros, falhas e fraudes), pelos sistemas de interfaces com o público externo e parceiros (WP, CRM e SCM) e pelos sistemas de informações gerenciais e estratégicas (DW, BI, GCI e GAI). Em geral, o grupo dirigente tem acesso aos SIs da organização por meio de seus assessores e consultores internos, que têm acesso aos SIs de conteúdos gerenciais e estratégicos.

Os SIs voltados para GCI podem ser, por exemplo, os de bancos de talentos, de colaboração, de grupos de interesse, de comunidades de prática e outros (materializados em SIs como os OLTP, DW, workgroup, blogs, listas de discussão, páginas de intranet etc). Os SIs de GAI podem ser bancos de dados especializados em conteúdos estruturados e indexados, tais como bibliotecas de documentos digitais ou digitalizados, arquivos em geral (nos conceitos de archives e files) e outros. Os conceitos de GCI e GAI, nas organizações do serviço público, tendem a se confundir, resultando apenas em GCI à medida que os ativos intangíveis são, basicamente, o conhecimento tácito dos servidores públicos mais experientes e capazes.

Os SIs identificados como ERP e ECM constituem a cola que conecta todas as unidades de gestão às fontes de informações internas armazenadas nos bancos de dados dos SIs da organização, transacionais (OLTP) ou gerenciais e estratégicos. O ERP propicia o acesso às informações com uma visão de planejamento de cima para baixo, enquanto o ECM garante o acesso às informações sobre fluxos e conteúdos diversos em uma visão de baixo para cima na estrutura da organização (integrando e agregando em um único sistema informações de todos os formatos). Os SIs $\mathrm{ECM}^{*}$, em

\footnotetext{
* Os sistemas computacionais ECM têm várias funcionalidades, tais como: automação de fluxos de trabalho (workflow), recursos de digitalização de documentos, gerenciamento eletrônico de documentos (GED), gerenciamento de mensagens de correio eletrônico, gerenciamento de conteúdos de Web Portal, recursos de indexação e busca de arquivos e conteúdos digitais, recursos de comunicação e colaboração, gerenciamento de arquivos digitais ou em outro suporte e bibliotecas digitais.
} 
particular, propiciam a automação de fluxos de trabalho (função de workflow) com arquivos de documentos digitais ou digitalizados acoplados aos fluxos, controlando-se a tramitação de processos documentais e decisões dos gestores sem manuseio de informações com suporte papel.

Os blocos de construção são dispostos, no modelo da figura 1, envolvendo grupos de usuários e respectivos SIs de modo que cada grupo de usuário tenha interface próxima aos seus blocos de SIs predominantemente utilizados. O bloco principal do modelo, para onde deverão convergir todos os esforços de uma Ofic no serviço público, seria o de Gestão de Processos de Negócio, no qual estariam contidas as estruturas horizontalizadas (ou matriciais) de liderança (monitoramento), expertise (especialistas em processos) e operação de todos os processos da organização destinados ao atendimento da clientela de usuários externos e internos. As Ofics públicas seriam, portanto, organizações centradas no atendimento de demandas externas operando com orientação a processos.

Outro bloco importante para a operação das Ofics no setor público seria o de Gestão Interna, responsável pelo provimento de recursos a toda a organização segundo o modelo burocrático de transação e suas instituições de comando e controle. Esse bloco teria a missão de operar os sistemas orgânicos de gestão de pessoas, orçamento e finanças, logística, patrimônio, licitações e contratos, engenharia e outros porventura relativos às tradicionais áreas-meio da administração pública. $O$ detalhe de inovação nessa área seria a modelagem e integração completa de todos os seus processos num SI corporativo, com funções típicas dos pacotes de softwares integradores conhecidos no mercado como Enterprise Resource Planning (ERP) e Enterprise Content Management (ECM).

Em termos de interfaces pessoais (pessoa a pessoa), o grupo de gestores de processos de negócio teria acesso direto aos gestores do atendimento, que são responsáveis pelo contato direto com a clientela, com os gestores de recursos internos, que são responsáveis pelo suprimento das demandas de insumos para o atendimento da clientela, com os membros do Conselho de Cidadãos, para conhecimento da avaliação do público sobre os serviços, e com todos os SIs da organização por meio dos SIs integradores ERP e ECM.

O bloco de Direção Política, pela efemeridade de seus membros nas respectivas posições, atuaria mais como intérprete das decisões políticas de governo na organização, repassando para os níveis hierárquicos
FIGURA 1

Blocos de Construção de Ofics no Serviço Público

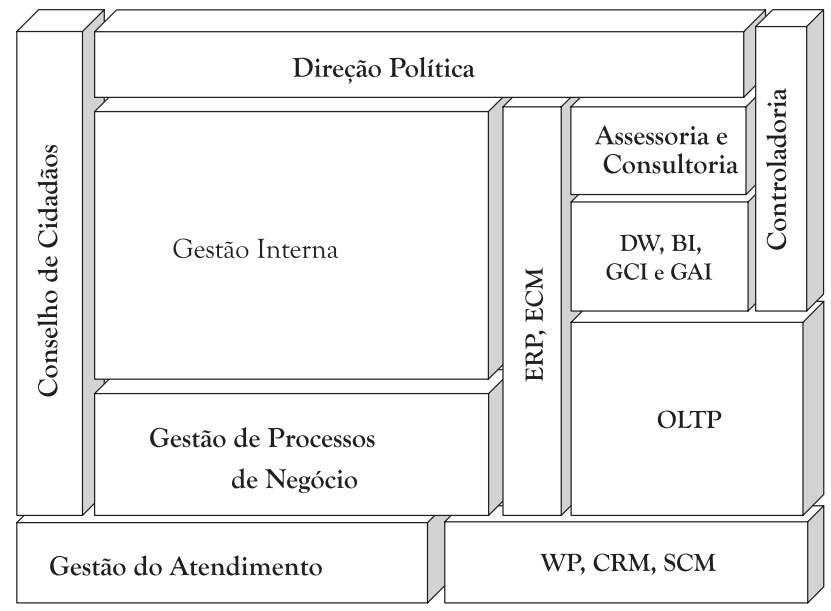

abaixo diretrizes impactantes nos projetos e ações programados ou a programar/planejar. Esse grupo atuaria com base em um modelo de governança colegiada, no qual todos os diretores teriam o direito de opinar e votar em todas as questões corporativas que chegassem até o nível de diretoria para decisão.

Os blocos do Conselho de Cidadãos e da Gestão do Atendimento, no modelo Ofic, devem atuar como captadores e estruturadores de demandas externas provindas dos usuários dos serviços e do resto da sociedade em geral, com a missão de apresentá-las à direção política e aos gestores internos da organização. Com essa dupla abertura para o resto do mundo, espera-se submeter a Ofic à pressão contínua da sociedade democrática em busca de cidadania, pressão esta que será o combustível para o motor das mudanças necessárias no futuro. Os contatos institucionais do Conselho de Cidadãos com a Ofic deverão envolver, além dos dirigentes políticos, os gestores internos como intérpretes mais qualificados, tecnicamente, do que os dirigentes políticos.

Quanto ao bloco de Gestão do Atendimento, ele deverá se basear em SIs especializados na captação de informações sobre a eficiência e a qualidade do atendimento, tais como Web Portal (WP) corporativo interno e externo, Customer Relationship Management (CRM) e Supply Chain Management (SCM), gerando bases de informações estruturadas e não estruturadas para monitoramento e controle dos processos operacionais de atendimento aos usuários dos serviços. O sistema de ouvidoria clássico se encaixa na classe de sistemas CRM, e os sistemas SCM são inovações (copiadas das grandes empresas do mercado) para integração de parceiros em geral (fornecedores do mercado, por exemplo) aos 
processos de negócio em modelos de provimento de recursos (insumos de produção) conhecidos como justin-time (JIT).* Essas bases de dados e informações de processos de atendimento seriam, então, estruturadas, em uma visão mais gerencial, em SIs conhecidos como Data Warehouse (DW), cujos acessos seriam disponibilizados para todos os membros da organização segundo sua necessidade, especialmente para os diretores, gestores internos, controladores, assessores e consultores internos.

O bloco Controladoria é clássico no modelo burocrático, mas, além de sua missão precípua de controle interno, teria missões mais ricas no modelo de Ofic proposto, tais como:

I. transformar os resultados dos achados de auditoria em informação relevante para os tomadores de decisão tanto no bloco de direção política quanto no bloco de gestão interna, conectando-se ao modelo de gestão de modo contínuo e sistêmico, visando à retro-alimentação dos sistemas de planejamento e gestão;

II. contribuir para a modelagem de processos nos aspectos relativos à segurança operacional das transações da organização com sua clientela externa (usuários de serviços, parceiros e o público em geral); isso implica modelar e codificar todas as regras de negócio em linguagem computacional;

III. contribuir para a construção de mecanismos de governança corporativa em todos os aspectos gerenciais e operacionais da organização, com base na experiência histórica de piores práticas observadas em auditorias e melhores práticas de gestão consagradas em cada objeto, processo ou atividade do negócio, ou de suporte do negócio (relativa ao bloco Gestão Interna).

O objetivo dessa ampliação da missão institucional da controladoria é o aperfeiçoamento dos processos e SIs das organizações públicas, implementando-se em softwares eficientes todas as regras de negócio e respectivos níveis de autoridade e responsabilidade dos diretores políticos, gestores internos, supervisores, monitores e operadores de processos de atendimento. Com isso, restariam satisfeitos, com processamento automático, os preceitos básicos do modelo hierárquico-burocrático e os requisitos de maior eficiência no processamento de transações.

O bloco Assessoria e Consultoria representa uma inovação do modelo Ofic em relação aos modelos

\footnotetext{
* O uso de sistemas de provimento bastante próximos ao JIT do mercado se tornou viável no serviço público graças à instituição do Sistema de Registro de Preços (SRP), com a Lei no 10.520/2002.
}

clássicos de estruturas organizacionais no serviço público, e, embora assessores existam em todas as organizações do serviço público, consultores internos são raros, geralmente atuando de modo informal. Os consultores seriam recrutados, com critérios técnicos bastante rigorosos, entre os servidores públicos da própria organização ou de outras organizações do serviço público com experiência e formação acadêmica adequadas, compondo um corpo técnico capacitado para a realização de estudos e pesquisas e aconselhamento técnico dos gestores e operadores do negócio em geral.

O conhecido conceito de Escritório de Gerenciamento de Projetos (Project Management Office, ou PMO), por exemplo, poderia ser implantado na organização com base na estrutura desse bloco. $\mathrm{O}$ caminho da consultoria interna também representa a concretização de uma antiga reivindicação corporativa de servidores públicos no sentido de se abrirem oportunidades de ascensão na carreira sem a necessidade de trilhar o caminho clássico da assunção de cargos de gerência ou direção. Ou seja, um servidor público com bastante conhecimento acadêmico e experiência profissional acumulada ao longo dos anos poderia ascender em uma carreira em Y como a proposta no modelo, tornando-se consultor interno.

O arsenal de informações dos consultores internos deverá ser constituído de todos os sistemas da organização, para os quais eles deverão ter acesso amplo. Os consultores deverão também participar ativamente na modelagem de novos SIs, contribuindo para o aperfeiçoamento dos processos de desenvolvimento de software com abordagens pragmáticas de solução de problemas. E deverão, também, participar das estruturas virtuais de governança corporativa da organização como fiel da balança em questões polêmicas sobre gestão, inclusive as relacionadas com TIC, unindo-se aos controladores como unidade corporativa de resistência orgânica contra o perpetramento de medidas danosas ao interesse público.

Espera-se, também, no modelo proposto, que os consultores e controladores atuem como gatekeepers das Ofics no serviço público, acumulando informações de dentro e dos ambientes externos da organização e promovendo a troca de informações entre ambos, de acordo com as necessidades da organização e o interesse público. O seu papel, portanto, é vital para o desenvolvimento de uma Ofic no setor público, devendo ser resguardado das intempéries políticas com algum dispositivo legal de proteção contra afastamentos de suas funções motivados por opiniões técnicas que contrariem interesses sectários, ou interesses não republicanos. 
E um dos segredos para viabilização do modelo Ofic no serviço público é o da integração dos repositórios de dados e informações sobre as transações do negócio, identificado no modelo como SIs OLTP (acrônimo de On Line Transaction Processing). Os SIs OLTP são baseados em computadores desde seu nascimento conceitual na década de 1960 e constituem, atualmente, um dos gargalos à modernização dos SIs nas organizações públicas em geral.

Os problemas com esse tipo de SI legado se devem, geralmente, (i) à visão departamental das aplicações, que espelham os silos da organização hierárquica e burocrática, com pouca ou nenhuma integração horizontal com outros sistemas computacionais de uma mesma organização, (ii) às TICs obsoletas que os suportam e (iii) à própria concepção arcaica dos modelos desses SIs, concebidos no passado unicamente para a automação de processos básicos de transações do negócio, na maioria voltados para transações departamentais das áreas meio. As TICs obsoletas desses SIs muitas vezes tornam inviável o desenvolvimento de sistemas de informação estratégicos e gerenciais de qualquer natureza, como OLAP*, DW, BI e outros, em razão das dificuldades na extração de blocos de dados de suas bases e acesso dos usuários pela WWW e Internet.

Outros repositórios de informações poderão ser criados em uma Ofic para suporte às atividades de seus membros, como os ilustrados na figura 2. Alguns têm funcionalidades comumente encontradas em portais (WP) corporativos atualmente, como bases de dados tradicionais, páginas web estáticas e dinâmicas (Web Pages), listas de discussão, fóruns, perguntas e respostas mais freqüentes (Frequent Asked Questions - FAQ) e bases de informação de legislação, enquanto outros ainda dependem de evolução nos ambientes informacionais e tecnológicos da maioria das organizações no serviço público, como os de bases de textos (bibliotecas digitais), de narrativas, de gerenciamento de ativos digitais (Digital Asset Management, ou DAM), de documentos (Document Management, ou DM) e de mensagens de correio eletrônico (E-mail Management, ou EM). Deve-se ressaltar, neste ponto, a importância de um tratamento adequado das informações legadas de arquivos em mídia papel.

Os SIs mais sofisticados, nesse cenário, são os de bases de regras (Rule-Based System, ou RBS) e de casos (CaseBased Reasoning, ou CBR), que utilizam, geralmente,

* OLAP: Sistema de Processamento Analítico em Linha ( On Line Analytical Processing); esse tipo de SI computacional se destina a integrar visões de informações gerenciais consolidadas a partir dos conteúdos de bancos de dados dispersos dos SIs OLTP em uma organização.
FIGURA 2

Repositórios de Informação para Suporte a Ofics

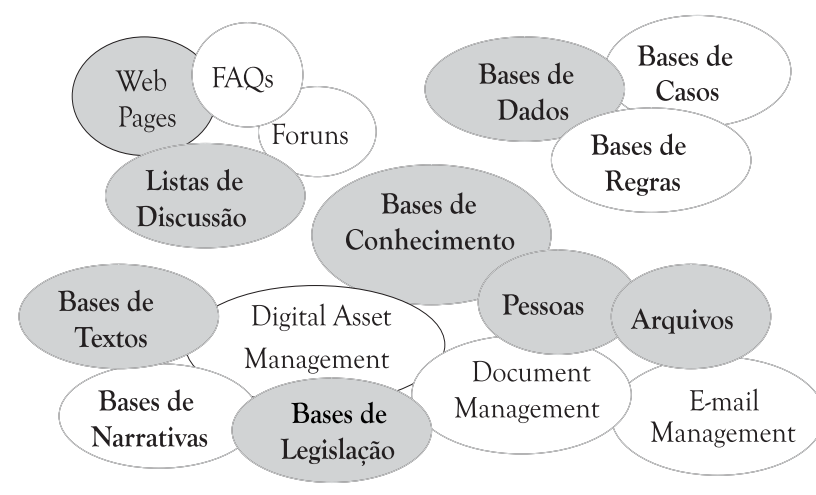

modelos ontológicos complexos para estruturação de seus conteúdos e dos mecanismos computacionais de armazenamento, atualização e consulta (DHAR; STEIN, 1997). Os RBS são muito úteis em contextos de processos de tomada de decisão, seja em nível estratégico ou no chão-de-fábrica das organizações, geralmente vinculados a procedimentos (regras) específicos contidos em processos de trabalho complexos e dispendiosos. Os SIs CBR geralmente se inserem em contextos de projetos complexos considerados no todo, que demandam avaliação de custos e cronogramas com algum grau de precisão, pelo vulto dos orçamentos envolvidos, como nas obras de engenharia de infra-estrutura patrocinadas pelo erário. O conjunto de SIs inteligentes que buscam auxiliar os processos de decisão nas organizações é atualmente conhecido, no mercado, como de Inteligência de Negócios (Business Intelligence ou BI), alguns deles utilizando recursos metodológicos e tecnológicos emprestados da inteligência artificial (IA).

Entretanto, esses SIs não seriam muito úteis sem o usuário humano com capacidade de interpretação dos resultados do processamento de dados e informações de suas bases. É nesse ponto do processo de trabalho com SIs em uma Ofic que entram, de modo bastante simples e pragmático, os conceitos de Gestão do Capital Intelectual (GCI) e de Gestão de Ativos Intangíveis (GAI) na figura 1.

O modelo parte do pressuposto que com SIs de qualidade adequada e pessoas com capacidade intelectual suficiente as Ofics poderão se tornar organizações onde o aprendizado se incorpore à sua cultura de modo espontâneo e natural, sem modelos mirabolantes e incompreensíveis de gestão do conhecimento. Ou seja, com oferta adequada de informações e pessoas com capacidade para compreendê-las e interpretá-las de acordo com seus construtos cognitivos e emocionais, 
poder-se-á iniciar um círculo virtuoso de aprendizado nas organizações para aprimoramento dos processos de tomada de decisão.

Conforme Choo (2003), em uma Ofic o conhecimento organizacional emergirá quando os três modos de usar a informação - criação de significados, construção do conhecimento e tomada de decisões conectarem-se para constituir uma rede maior de processos que continuamente gerarão significados, aprendizado e ações concretas. O conhecimento, em uma Ofic do serviço público como proposta, será sempre tácito, no conceito de Nonaka e Takeuchi (1997), e armazenado, conforme Drucker (1994), em um repositório neural que se situa entre duas orelhas, mas também disponível à medida que as pessoas têm estabilidade no emprego e seus empregos são para a vida toda.

O conhecimento resulta do processamento de informações pelo ser humano e a aceitação de algo novo em sua base cognitiva preexistente, de modo semelhante ao modelo matemático de Brookes (1980), conceito que não pode ser dissociado da noção de aprendizado da psicologia e, portanto, um processo bastante difícil, senão impossivel, de ser gerenciado.

\section{Modelo de conexão}

O modelo de conexão esboçado na figura 3 se refere às necessidades de interfaces entre as Ofics de um mesmo nível de governo, ou entre Ofics de diferentes níveis de governo, para o provimento de serviços eletrônicos ponta a ponta (completo) ao usuário-cidadão. As interfaces de navegação dos usuários entre os SIs internos na organização deverão ser implementadas nos Web Portais (WPs), que deverão ser amigáveis e completos do ponto de vista do atendimento das necessidades do público interno de uma Ofic. Os WPs permitem acessar, mediante interfaces padronizadas e seguras, todos os SIs existentes e implementar e integrar, ainda, os sistemas de comunicação de informação (SCI) corporativos como correio eletrônico, VoIP (telefonia via Internet), videoconferência, etc.

Os WPs precisam, em uma Ofic, atingir o estágio 4 na escala de desenvolvimento de e-Gov, proporcionando um amplo locus de realização de transações eletrônicas completas entre a organização e o seu público interno e externo, integrando inclusive os sistemas bancários e outros necessários em cada caso. Os controles de transações deverão, no entanto, ser totalmente transparentes para os usuários e baseados em regras bem definidas e inteligentes de permissão de acesso e registros (logs) de processamento eletrônico para a disponibilização de trilhas de auditoria.

Quanto às interfaces com outras Ofics, a figura 3 apresenta um modelo pictórico de blocos onde as conexões se realizam, virtualmente, por meio de SIs de atendimento. Contudo, para que as Ofics possam gerir adequadamente essas conexões virtuais e até implantar estruturas virtuais de gestão dos SIs compartilhados, ou produzidos a partir dessas conexões, em modelos hipertexto ou similares (NONAKA; TAKEUCHI, 1997), poderão existir unidades em cada Ofic que compartilhem missões comuns com outras Ofics.

Observando-se o acoplamento proposto na figura 3, deduz-se que as conexões entre Ofics serão simétricas, ou seja, as áreas a serem conectadas serão comuns entre as organizações conectadas, partindo dos blocos de Gestão do Atendimento e seus SIs de apoio (CRM e SCM). Os serviços públicos envolvendo interação com o cidadão e baseados em mashups", uma tendência na WWW, deverão ser suportados por esse tipo de infraestrutura tecnológica.

\section{FIGURA 3}

Conexões Virtuais de Serviços entre Ofics

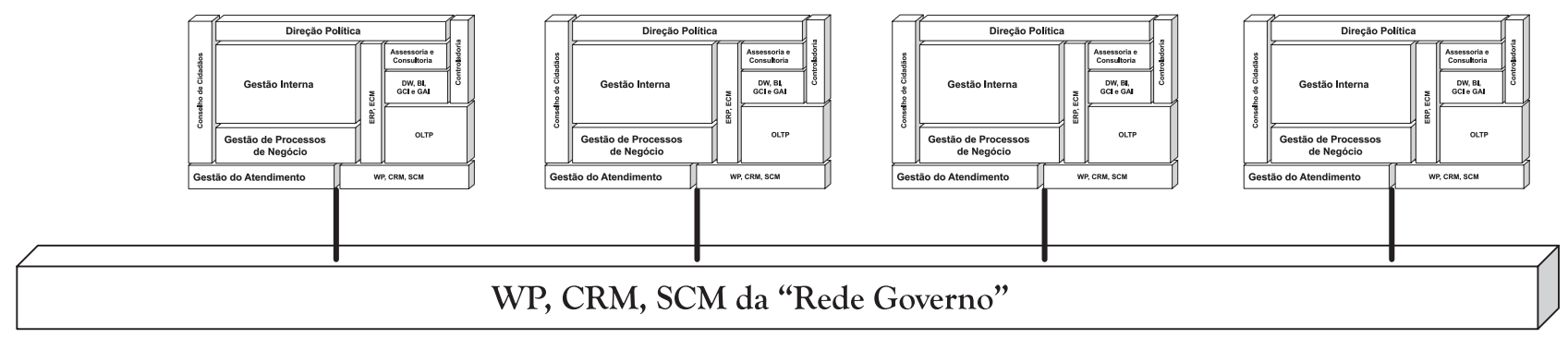

* Website que utiliza conteúdos de informação de mais de uma fonte na WWW para criar um serviço completo. 


\section{Estratégias de Implantação}

Obviamente, várias estratégias de implantação do modelo Ofic poderão ser utilizadas e será difícil avaliar, a priori, qual a melhor opção, pois cada uma será, naturalmente, adequada a cada caso. Contudo, algumas políticas têm sido mais recomendadas em termos gerais, propondo-se os seguintes passos no planejamento dessa empreitada:

I. encantar, envolver e conceder autoridade e responsabilidade (empoderamento) ao pessoal da base da pirâmide hierárquica em relação aos projetos, tornando-o o próprio governante dos projetos e responsáveis diretos pelos resultados decorrentes;

II. montar times e dar aos gerentes e pessoal da base meios para desenvolverem, do ponto de vista prático, os conceitos do projeto, colocando-o em ação;

III. elicitar, paulatinamente, os ativos de informação e conhecimento da organização e mostrar seu valor para o projeto aos gerentes de média posição e ao pessoal da base;

IV. capacitar os envolvidos no projeto para superação de lacunas em conhecimentos temáticos, promovendo o lema aprender a aprender;

V. resolver os maiores "gargalos" de informação, de TIC e de processos em todas as áreas operacionais e gerenciais;

VI. reorganizar a estrutura administrativa de baixo para cima (processo bottom-up), em um modelo misto matricial-hipertexto-hierárquico-participativo;

VII. montar, gradualmente, o novo lego da arquitetura organizacional e informacional e iniciar sua implementação com suporte de SIs computacionais;

VIII. desenvolver uma cultura de GI, GCI e GAI na organização a partir de seu valor de uso (abordagem de solução de problemas), com incentivos à inovação e melhoria contínua.

Em termos de modelo evolutivo, talvez a melhor estratégia seja a proposta pelo Pacific Council on International Policy (2002) para a implantação de projetos de Governo Eletrônico: pense grande, inicie pequeno, escale rapidamente.

\section{CONCLUSÕES E QUESTÕES EM ABERTO}

Existe atualmente uma profusão de idéias no mundo todo sobre as conexões necessárias entre serviços públicos, democracia, cidadania, informação, TIC e administração pública, tema complexo que tem despertado o interesse da academia como área de conhecimento multidisciplinar. $\mathrm{O}$ artigo mostrou como essas conexões podem se tornar explícitas do ponto de vista da informação como o princípio organizador das coisas e, no caso, como o elo entre as diversas dimensões epistemológicas do estudo das organizações públicas.

Equívocos axiomáticos basilares impedem a concretização de projetos de reformas na administração pública para tornar os serviços públicos melhores e mais eficientes, tais como a concentração de críticas sobre o modelo hierárquico-burocrático, ignorando-se os pontos fortes desse modelo secular ante os modelos alternativos, tendo-se gerado antagonismos estéreis entre teses burocráticas e gerencialistas.

Em contraponto, a ciência da informação dispõe de base epistemológica suficiente para tratamento do tema além dos conflitos ideológicos que hoje permeiam discussões sobre as propostas mais conhecidas de reformas, em especial as da corrente Nova Gestão Pública (NPM), podendo oferecer a cola necessária para uma síntese conceitual que possa fazer avançar os debates. Esse elemento aglutinador seria composto por conceitos de arquitetura da informação e experiências de gestão da informação, apoiada pelo uso intensivo de TICs, e gestão de pessoas (ou de capital intelectual), com foco na valorização do aprendizado dos membros permanentes de uma organização do serviço público. O objetivo geral seria alavancar, efetivamente, a modernização dos serviços públicos de modo a atender aos requisitos de seus usuários e da população em geral, especialmente o da integração de serviços ponta-a-ponta (interdepartamental) na Web, pela Internet, e o da transparência dos processos decisórios (e não apenas das decisões em si).

- modelo genérico de organização fundamentada na informação e no conhecimento (Ofic) proposto, inspirado nas idéias de Drucker (1994), Bobbio (1995) e de governo eletrônico e com base em um diagnóstico estrutural dos pontos fortes e fracos da estrutura do aparelho de Estado no Brasil, poderá contribuir para a evolução do debate e a construção de bases epistemológicas em ciência da informação para tratamento adequado do problema. Com a visão de blocos ou legos de conteúdos de informação nas Ofics, pode-se planejar os espaços e interfaces conversacionais entre os diversos públicos internos e externos envolvendo patrocinadores, diretores, gerentes, operadores e usuários dos processos de serviços. Essa abordagem analítica também poderá facilitar o recorte 
de componentes padronizados de sistemas de informações computacionais (SICs) e o desenvolvimento de estratégias adequadas de implementação para cada caso, considerando-se que os requisitos de conteúdos de informação e de interfaces de integração com outros aplicativos de software estarão bem definidas. A metáfora do lego organizacional identificado nos blocos de informação e suas interfaces recíprocas também é útil à medida que mostra, com clareza, os pontos de contato entre as unidades de gestão interna em uma Ofic e os respectivos espaços conversacionais necessários. Os blocos desse lego significam, ao mesmo tempo, recortes da cultura organizacional e conteúdos de informação corporativa a serem trabalhados.

Os conteúdos temáticos ainda desafiam pesquisadores e podem motivar trabalhos posteriores mais aprofundados em linhas de pesquisas como as seguintes: (i) modelagem de ontologias de negócio e respectivos repositórios corporativos para o aprendizado nas Ofics; (ii) integração matricial de serviços e processos de atendimento ao público em organizações governamentais; (iii) ampliação da transparência de processos e informações de governo, na abordagem de governo eletrônico, como meio de combate à corrupção no serviço público; (iv) gestão do capital intelectual em projetos de reengenharia nos órgãos públicos; (v) consolidação e integração lógica de modelos e bases de dados e informações legadas; (vi) gestão do atendimento com uso de sistemas de inteligência de negócios (BI) no serviço público; (vii) desenvolvimento de uma cultura de aprendizado contínuo nas organizações públicas; (viii) desenvolvimento de políticas de recrutamento, seleção e retenção de talentos em gestão da informação e de TIC para gestão de serviços nas organizações públicas.

Como última questão em aberto, talvez a mais desafiadora, resta a inclusão de temas de gestão nas agendas dos partidos políticos no Brasil, que poderia ocorrer a partir de discussões mais pragmáticas, tais como o risco de perda acentuada de capital intelectual na próxima década e de deterioração acelerada das condições de trabalho nas organizações públicas, com prejuízos para todos, inclusive os próprios partidos políticos hegemônicos. $\mathrm{O}$ efetivo estabelecimento da alça de retroalimentação sistêmica de informações da função controle aos processos de planejamento nas organizações governamentais talvez seja o primeiro passo nesse aprendizado histórico.

Artigo submetido em 07/10/2008 e aceito em 26/12/2008.

\section{REFERÊNCIAS}

ABRÚCIO, Luiz Fernando. Palestra na Escola Nacional de Administração Pública: 20 anos da aula inaugural da $1^{\text {a }}$ turma de Especialistas em Políticas Públicas e Gestão Governamental (EPPGGs). Brasília: ENAP, 2008.

ALMEIDA, Cleverson Pereira de. Custo humano, estratégias de mediação e cidadania: atendimento presencial ao público em agências da Previdencia Social. 2007. Tese (Doutorado em Psicologia Social, do Trabalho e das Organizações)- Universidade de Brasília, Brasília, 2007.

ALTMAN, Fabio. Sua empresa é uma orquestra?. Época Negócios. Disponível em: <http://epocanegocios.globo.com/Revista/.../ 0,,DR77944-8374,00.html>. Acesso em: 26 out. 2007.

ASHRAF, Manzur; ALI, Humayra Binte; ASHRAF, Md. Mahfuz. Cyclic knowledge management system in e-governance: a case study of evaluating polls on referendum-independence of Quebec using ANN. SIGMIS-CPR, Georgia, v. 5, p. 14-16, Apr. 2005.

BABILON, Maria. The evolution of knowledge management within NCR Corporation. Association for Computing Machinery, 1998.

BALANCO, Paulo; LEONY, Maria das Graças Sá. Governo eletrônico e rede intergovernamental de informações. In: CINFORM ENCONTRO NACIONAL DE CIÊNCIA DA INFORMAÇÃO, 6., 2007. Anais eletrônicos... Disponível em: 〈http://www.buscalegis.ufsc.br/ arquivos/Douglas07-11-2006-12.pdf>. Acesso em: 13 dez. 2007.

BARBARÁ, Saulo (Org.). Gestão por processos: fundamentos, técnicas e modelos de implementação. Rio de Janeiro: Qualitymark, 2006.

BARBOSA, Alexandre Fernandes; FARIA, Fernando Inácio de; PINTO, Solon Lemos. Governança eletrônica no setor público. In: KNIGHT, Peter Titcomb; FERNANDES, Ciro Campos Christo; CUNHA, Maria Alexandra (Org.). E-desenvolvimento no Brasil e no mundo: subsídios e programa e-Brasil. São Caetano do Sul, SP: Yendis, 2007. p. $512-537$.

BATES, Marcia J. The invisible substrate of information science. Disponível em: 〈http://www.gseis.ucla.edu/research/bates1.html >. Acesso em: 15 set. 2007.

BATISTA, Fábio Ferreira. Governo que aprende: gestão do conhecimento em organizações do executivo federal. Brasília: IPEA, 2004. Disponível em: 〈http://www.ipea.gov.br/pub/td/2004/td 1022.pdf $>$. Acesso em: 02 dez. 2007.

BHATNAGAR, Subhash. Transparency and corruption: does e-government help?. Draft for the CHRI 2003 Report OPEN SESAME: looking for the Right to Information in the Commonwealth, Commonwealth Human Rights Iniciative, 2003. Disponível em: < $\underline{\text { http:// }}$ www.iimahd.ernet.in/ subhash/pdfs/CHRIDraftPaper2003.pdf $>$. Acesso em: 10 set. 2008 .

BOBBIO, Norberto. Il futuro della democrazia. 3. ed. Torino: Giulio Einaudi, 1995.

BOX, R. C. Citizen governance: leading american communities into the 21st century. Thousand Oaks: SAGE, 1998.

BRASIL. Ministério da Administração Federal e Reforma do Estado. Questões sobre a reforma administrativa: resposta a um parlamentar. Brasília, [200?].

. Ministério do Planejamento, Orçamento e Gestão. Boletim estatístico de pessoal. 2007. Disponível em: < $\underline{\text { http:// }}$ www.planejamento.gov.br>. Acesso em: 20 jun. 2008. 
BRESSER PEREIRA, Luiz Carlos. Reforma do aparelho do estado para cidadania: a reforma gerencial brasileira na perspectiva internacional. São Paulo: Editora 34; Brasília: ENAP, 1998.

BROOKES, Bertram C. The foundations of information science: part I: philosophical aspects. Journal of Information Science, n. 2, p. 125-133, 1980.

CAMPOS, Luiz Fernando de Barros. Análise da nova gestão do conhecimento: perspectivas para abordagens críticas. Perspectivas em Ciência da Informação, v. 12, n. 1, p. 104-122, jan./abr. 2007.

CAPUANO, Ethel Airton. Redesenho de processos e estruturas nas organizações da administração pública. In: KNIGHT, Peter T.; FERNANDES, Ciro C. C.; CUNHA, Maria A. (Org.). E-desenvolvimento no Brasil e no mundo: subsídios e Programa e-Brasil. São Caetano do Sul: Yendis, 2007. p. 585-623.

CARVAlHO, José Murilo de. A construção da ordem e teatro de sombras. 2. ed. Rio de Janeiro: UFRJ, 1996.

CANADIAN CENTRE FOR MANAGEMENT DEVELOPMENT CCMD. A primer on knowledge management in the public service. Disponivel em: $\quad$ http://www.krii.com/downloads/ $\mathrm{km}$ in public admin rev.pdf $>$. Acesso em: 15 nov. 2007.

CHOO, Chun Wei. A organização do conhecimento: como as organizações usam a informação para criar significado, construir conhecimento e tomar decisões. Tradução de Eliana Rocha. São Paulo: SENAC, 2003.

Towards an information model of organizations. The Canadian Journal of Information Science, v. 16, n. 3, 1991, p. 32-62.

CONG, Xiaoming; PANDYA, Kaushik V. Issues of knowledge management in the public sector. Academic Conferences Limited, 2003. Disponivel em: 〈http://www.ejkm.com/volume-1/volume1-issue-2/ issue-2-art-3-cong-pandya.pdf $>$. Acesso em: 15 nov. 2007.

DHAR, Vasant; STEIN, Roger. Seven methods for transforming corporate data into business intelligence. Prentice-Hall, 1997.

DAVENPORT, T. H.; PRUSAK, L. Conhecimento empresarial: como as organizações gerenciam o seu capital intelectual. 4. ed. Rio de Janeiro: Campus, 1998.

DRUCKER, Peter F. The coming of the new organization: harvard business review on knowledge management, Harvard Business School, p. 1-19, 1998.

-__-_-_. The new realities. Butterworth-Heinemann, Jan. 1994.

GOMES, Angela de Castro; DIAS, José Luciano de Mattos; MOTTA, Marly Silva (Coord.). Engenheiros e economistas: novas elites burocráticas. Rio de Janeiro: FGV, 1994.

GORE, Al. Common sense government: works better \& costs less. Washington (DC): US Government Printing Office, 1994.

GRAHAM, Richard. Clientelismo e política no Brasil do Século XIX. Tradução de Celina Brandt. Rio de Janeiro: UFRJ, 1997.

HEMSLEY, J. R.; VASCONCELLOS, E. Estrutura das organizações: estruturas tradicionais, estruturas para inovação, estrutura matricial. 3. ed. São Paulo: Pioneira, 1997.

HOMBURG, Vincent. E-government and NPM: a perfect marriage?. In: JANSSEN, Marijn; SOL, Henk G.; WAGENAAR, René (Ed.). ICEC'04 - International Conference on Electronic Commerce. 6., 2004. Proceedings... Association for Computing Machinery, 2004.

HOOD, Christopher. The "New Public Management" in the 1980s: variations on a theme. Workshop on "Changing Notions of
Accountability in the U.K. Public Sector". LSE, dez. 1991. Accounting Organizations and Society, v. 20, n. 2/3, 1995, p. 93-109.

HOSKINS, D. D.; DOBBERNACK, D.; KUPTSCH, C. (Ed.). Social security at the dawn of the $21^{\text {st }}$ Century. [S. 1.]: International Social Security Association, 2001.

HOPKINS, Jeffery A. Matrix: an alternate organization structure for the exchange and processing of information. [S. 1.]: Association for Computing Machinery, 1982.

KENT, Robert E. The information flow foundation for conceptual knowledge organization. Disponível em: <http://www.ontologos.org/Papers/ ISKO6/ISKO6.pdf>. Acesso em: 15 nov. 2007.

KIM, Soonhee; LEE, Hyangsoo. Organizational factors affecting knowledge sharing capabilities in e-government: an empirical study. [S.1]: Association for Computing Machinery, 2006.

KNELLER, George F. A ciência como atividade humana. Tradução de Antônio José de Souza. Rio de Janeiro: Zahar; São Paulo: EDUSP, 1980 .

KNIGHT, Peter Titcomb; FERNANDES, Ciro Campos; CUNHA, Maria Alexandra. Experiências internacionais e brasileiras de edesenvolvimento e caminhos para o e-Brasil. In: KNIGHT, Peter Titcomb; FERNANDES, Ciro Campos Christo; CUNHA, Maria Alexandra (Org.). E-desenvolvimento no Brasil e no mundo: subsídios e programa e-Brasil. São Caetano do Sul, SP: Yendis, 2007a. p. 31-56.

(Org.). E-desenvolvimento no Brasil e no mundo: subsídios e programa e-Brasil. São Caetano do Sul, SP: Yendis, 2007b.

LIMA-MARQUES, Mamede; MACEDO, Flávia Lacerda Oliveira de. Arquitetura da informação: base para a gestão do conhecimento. In: TARAPANOFF, Kira (Org.). Inteligência, informação e conhecimento. Brasília: IBICT, 2006. p. 241-255.

LODI, J. B. A estrutura matricial e a estrutura sistêmica: dois novos tipos de organização. Revista de Administração de Empresas - RAE, Rio de Janeiro, n. 4, p. 157-179, out./dez. 1970.

MAGALHÃES, Claudia. et al. Gestão do conhecimento: o DESENBANCO na era das organizações aprendizes. 2001. Disponível em: 〈http:// www.flem.org.br/premio/Projetos/2001/PFLEMPRJ10089.PDF>. Acesso em: 14 dez. 2007.

MARINI, Caio; MARTINS, Humberto. Um governo matricial: estruturas em rede para geração de resultados de desenvolvimento. In: CONGRESSO INTERNACIONAL DEL CLAD SOBRE LA REFORMA DEL ESTADO Y DE LA ADMINISTRACIÓN PÚBLICA. 9., 2004. Madrid, Espana, 2004. Anales electrónicos... Disponível em: <http://www.clad.org.ve/fulltext/0049617.pdf>. Acesso em: 15 nov. 2007.

MARTINS, Humberto Falcão. Introdução ao governo matricial: o problema da fragmentação. In: CONGRESSO INTERNACIONAL DEL CLAD SOBRE LA REFORMA DEL ESTADO Y DE LA ADMINISTRACIÓN PÚBLICA. 9., 2004, Madrid, Espana. Anales... 2004.

MASUDA, Yoneji. The information society as post-industrial society. Bethesda, USA: World Future Society, 1981.

MCINERNEY, Claire R. Compartilhamento e gestão do conhecimento: profissionais da informação em um ambiente de confiança mútua. Tradução de Ulf Gregor Baranow. In: TARAPANOFF, Kira (Org.). Inteligência, informação e conhecimento. Brasília: IBICT, 2006a. p. 57 72 .

METASTORM. Process-centred government: the road to 2010. Disponível em: $\quad<$ http://www.kerfi.se/admin/rwdx/.../Process- 
Centred Government The Road to 2010.pdf $>$. Acesso em: 15 nov. 2007.

MICHAUD, Claude. Modelos e conhecimento. In: TARAPANOFF, Kira (Org.). Inteligência, informação e conhecimento. Brasília: IBICT, 2006b. p. 211-239.

NONAKA, Ikujiro; TAKEUCHI, Hirotaka. Criação de conhecimento na empresa: como as empresas japonesas geram a dinâmica da inovação. Tradução de Ana Beatriz Rodrigues e Priscilla Martins Celeste. 16. ed. Rio de Janeiro: Elsevier, 1997.

OSBORNE, David; GAEBLER, Ted. Reinventando o governo: como o espírito empreendedor está transformando o setor público. Tradução de Sérgio Fernando Guarischi Bath e Ewandro Magalhães Júnior. 6 ed. Brasília: MH Comunicação, 1995.

PACIFIC COUNCIL ON INTERNATIONAL POLICY. Roadmap for e-government in the developing world: 10 questions e-government leaders should ask themselves. 2002. Disponível em: <http:// www.pacificcouncil.org/pdfs/e-gov.paper.f.pdf $>$. Acesso em: 10 set. 2008.

PALKOVITS, Silke; WIMMER, Maria A. Process in e-government: a holistic framework for modelling electronic public services. Disponivel em: < ht t p://www.adoamt.com/down loads/ Palkovits Wimmer Processes in EGov.pdf>. Acesso em: 15 nov. 2007.

PAWLOWSKI, Suzanne D.; DATTA, Pratim; HOUSTON, Andrea L. The (gradualy) changing face of state IT jobs. Communications of the ACM, v. 48, n. 5, May 2005.

PERROTTI, Edoardo. A estrutura organizacional como elemento facilitador da gestão do conhecimento. In: SEMEAD, 7., 2004, São Paulo. Anais... São Paulo: Faculdade de Economia e Administração da Universidade de São Paulo (FEA/USP), 2004.

PIEROZZI JR., Ivo; MIRANDA, Evaristo Eduardo de; CARVALHO, Carlos Alberto de. Gestão do conhecimento: integrando planejamento estratégico, organização e comunicação da informação na Embrapa Monitoramento por Satélite. In: CONGRESSO IBERO-AMERICANO DE GESTÃO DO CONHECIMENTO E INTELIGÊNCIA COMPETITIVA, 2006, Curitiba. Anais... Curitiba: [s. n.] 2006.

RAMANATHAN, Jay. Fractal Architecture for the Adaptive Complex Enterprise. Communication of the ACM, v. 48, n. 5, May 2005.

RIBEIRO, Érica Bezerra Queiroz. A gestão do conhecimento como referência de avaliação do uso de tecnologias de informação e comunicação no sistema de inteligência da segurança pública e no controle de gastos públicos no Brasil. 2007. Dissertação (Mestrado)- Universidade Federal de Santa Catarina, Santa Catarina. Disponível em: <http://www.cin.ufsc.br/.../ EricaRibeiro.pdf $>$. Acesso em: 14 dez. 2007.

RIECKEN, Rinalda Francesca. Governo eletrônico em administrações locais brasileiras: avaliação de progresso, fatores intervenientes e critérios de priorização de iniciativas. 2008. Tese (Doutorado em Ciência da Informação) - Universidade de Brasília, Brasília, 2008.

RITTO, Antonio Carlos. Organizações caórdicas: modelagem de organizações inovadoras. Rio de Janeiro: Ciência Moderna, 2005.

SALHOFER, Peter; FERBAS, David. A pragmatic approach to the introduction of e-government. In: ANNUAL INTERNATIONAL DIGITAL GOVERNMENT RESEARCH CONFERENCE, 8., 2006. Proceedings... [S. 1.]: Association for Computing Machinery, 2006.

SANTOS, Luiz Alberto dos. Reforma administrativa no contexto da democracia: a PEC nº 173/95, suas implicações e adequação ao Estado brasileiro. Brasília: DIAP, 1997.
SILVA, Ivanosca Andrade da. et al. Um framework para desenvolvimento de sistemas complexos. Disponivel em: 〈http:///www.dimap.ufrn.br/ bedregal/publications/publications Ivanosca.PDF>. Acesso em: 14 jun. 2004.

SOUZA, Iara Lis Franco Schiavinatto Carvalho. Pátria coroada: o Brasil como corpo político autônomo: 1780-1831. São Paulo: UNESP, 1999.

SPÄTH, Manfred. Retaining know-how in public service: knowledge management under conditions of demographic change. 2006. Disponivel em: <http://www.4qconference.org/liitetiedostot/ agora presentations/Agora4.1 Spaeth.pdf>. Acesso em: 15 nov. 2007.

SVEIBY, Karl-Erik. What is knowledge management?. 2001. Disponível em: $\quad<$ http://www.sveiby.com/Portals/0/articles/ KnowledgeManagement.html>. Acesso em: 15 nov. 2007.

TAKAHASHI, Sérgio; TAKAHASHI, Vania Passarini. Gestão de inovação de produtos: estratégia, processo, organização, conhecimento. Rio de Janeiro: Elsevier, 2007.

TARAPANOFF, Kira (Org.). Inteligência, informação e conhecimento. Brasília: IBICT, 2006a.

. Informação, Conhecimento e Inteligência em Corporações: relações e complementaridade. In: _-_-_-. (Org.). Inteligência, informação e conhecimento. Brasília: IBICT, 2006b. p. 19-35.

TEIXEIRA, Francisco M. P.; TOTINI, Maria Elizabeth. História econômica e administrativa do Brasil. 2. ed. São Paulo: Ática, 1991.

TRAUNMÜLLER, Roland; WIMMER, Maria. Knowledge management for government: enhancing the quality of public service. Institute of Applied Computer Science, University of Linz (Austria). DPADM/ UNDESA Ad hoc Group of Experts Meeting, 5 set. 2003. Disponivel em: <http://unpan1.un.org/intradoc/groups/public/documents/un/ unpan011793.pdf>. Acesso em: 15 nov. 2007.

USERO, José Angel Martínez; ORENES, Maria Pilar Beltrán. Ontologies in the context of knowledge organization and interoperability in e-government services. In: IRFD WORLD FORUM 2005 - CONFERENCE ON DIGITAL DIVIDE, GLOBAL DEVELOPMENT AND THE INFORMATION SOCIETY, 2005, Túnis (Tunísia). Electronic proceedings... Disponível em: <http:// eprints.rclis.org/archive/00006922/01/2005-IRFD-ontologiasmartinezusero.pdf>. Acesso em: 15 nov. 2007.

VALLS, Valéria Martin. O enfoque por processos da NBR ISSO 9001 e sua aplicação nos serviços de informação. Ciência da Informação, Brasília, v. 33, n. 2, p. 172-178, maio/ago. 2004.

VASCONCELOS, José Adirson de. A epopéia da construção de Brasilia. Brasília: Centro Gráfico do Senado Federal, 1989.

VOLBERDA, Henk W. Building the flexible firm: how to remain competitive. New York: Oxford University, 1998.

WEILL, Peter; ROSS, Jeanne W. IT governance on one page. 2004. Disponível em: <http://web.mit.edu/cisr/working\%20papers/ cisrwp349.pdf>. Acesso em: 16 dez. 2007.

WILSON, T. D. The nonsense of "Knowledge Management". Information Research, v. 8, n. 1, out. 2002.

WOLFF, Edward N. The growth of information workers in the U.S. economy. Communications of the ACM, v. 48, n. 10, Out. 2005.

ZELL, Deone. Projetado para mudar: inovação organizacional na HewlettPackard. Tradução de Marta Schmidt. Rio de Janeiro: Record, 1997. 